\title{
Health risks among shift workers: the need for a multipronged approach
}

Literature review shows that shift workers commonly experience difficulties with both sleep and alertness at a desired time. Shift work can lead to disruption of social and family wellbeing. Additionally, shift work has been linked to changes in dietary habits, and health risks such as psychological stress, metabolic disorders, diabetes, cancer, and cardiovascular diseases [1-3].

Many shift workers may be able to adjust their sleep-wake cycle to their work schedule. However, a substantial number of shift workers experience reduced total sleep time over a 24-h period, reduced sleep quality, duration, and excessive sleepiness when compared with workers who do not work shifts [4].

Portable sleep monitoring devices are useful tools to help determine the sleep-wake pattern in individuals over an extended period [5]. They can be used to define potential sleep problems and to monitor changes in sleep quality after interventions. Measures to improve sleep included nighttime nap strategies or regularized 3-4 h morning sleep (so-called "anchor" sleep) with a second variable time sleep period [6]. This may be combined with light blocking shades and ambient noise control. Some have proposed pharmacological interventions such as short acting agonists or melatonin for sleep improvement. However, the evidences supporting these proposals remain inconclusive [7] and measures are needed to mitigate the unwanted risks of pharmacological interventions, such as accidents, when these interventions are used. Nonpharmacological measures such as sleep scheduling and cognitive behavioral therapy should be explored initially [8].

In this issue, Ravibabu et al. [9] highlight the susceptibility of night-shift workers to an increased risk of metabolic syndrome and insulin resistance with adipokine measurement in industrial workers who work various schedules, including night shift. In addition to the measures suggested above to improve sleep, dietary, and lifestyle habits, exercise can be used as an additional measure to reduce the threat of metabolic disorders among night-shift workers in industry, particularly in societies already burdened with increased incidence of noncommunicable chronic diseases $[10,11]$. Shift work and its negative consequences are becoming more relevant as the economy and lifestyle become increasing globalized. In addition to the symptoms of sleep and excessive sleepiness, there are many consequences for health and daily functioning. Studies are required toward finding evidence-based recommendations for the clinical management of shift work, including comprehensive clinical assessments and intervention strategies that target multiple domains through pharmacological and nonpharmacological methods.

\section{References}

[1] Pepłońska B, Nowak P, Trafalska E. The association between night shift work and nutrition patterns among nurses: a literature review. Med Pr. 2019; 70:363-76.

[2] Rosa D, Terzoni S, Dellafiore F, Destrebecq A. Systematic review of shift work and nurses' health. Occup Med (Lond). 2019; 69: 237-43.

[3] Hansen J. Night shift work and risk of breast cancer. Curr Environ Health Rep. 2017; 4:325-39.

[4] Booker LA, Magee M, Rajaratnam SMW, Sletten TL, Howard ME. Individual vulnerability to insomnia, excessive sleepiness and shift work disorder amongst healthcare shift workers. a systematic review. Sleep Med Rev. 2018; 41:220-33.

[5] Markwald RR, Bessman SC, Reini SA, Drummond SPA. Performance of a portable sleep monitoring device in individuals with high versus low sleep efficiency. J Clin Sleep Med. 2016; 95-103.

*Correspondence to: Editorial Office of Asian Biomedicine, Faculty of Medicine, Chulalongkorn University, Bangkok 10330, Thailand, email:abmjournal@chula.ac.th

O Open Access. ๑ 2021 Editorial Office of Asian Biomedicine, published by Sciendo. (๔) BY-NC-ND This work is licensed under the Creative Commons Attribution NonCommercial-NoDerivatives 4.0 License. 


\section{RASIAN

[6] Takeyama H, Kubo T, Itani T. The nighttime nap strategies for improving night shift work in workplace. Ind Health. 2005; 43:24-9.

[7] Liira J, Verbeek JH, Costa G, Driscoll TR, Sallinen M, Isotalo LK, Ruotsalainen JH. Pharmacological interventions for sleepiness and sleep disturbances caused by shift work. Cochrane Database Syst Rev. 2014; (8):CD009776. doi: 10.1002/14651858.CD009776.pub2

[8] Richter K, Acker J, Adam S, Niklewski G. Prevention of fatigue and insomnia in shift workers-a review of non-pharmacological measures. EPMA J. 2016; 7:16. doi: 10.1186/s13167-016-0064-4.
[9] Ravibabu K, Jakkam S, Ravi Prakash J, Adepu, V. Association of industrial work schedules with development of metabolic syndrome, insulin resistance, and serum adipokine concentrations. Asian Biomed (Res Rev News). 2021; 15(2):69-77.

[10] Nea FM, Kearney J, Livingstone MBE, Pourshahidi LK, Corish CA. Dietary and lifestyle habits and the associated health risks in shift workers. Nutr Res Rev. 2015; 28:143-66.

[11] Gabriel BM, Zierath JR. Circadian rhythms and exercise - re-setting the clock in metabolic disease. Nat Rev Endocrinol. 2019; 15:197-206. 